\title{
Selective Scavenging Property of the Indole Moiety for the Nitrating Species of Peroxynitrite
}

\author{
Hidehiko Nakagawa, ${ }^{a}$ Mitsuko Takusagawa, ${ }^{a}$ Hiromi Arima, ${ }^{a}$ Kumiko Furukawa, \\ Takeshi Kinoshita, ${ }^{b}$ Toshihiko Ozawa, ${ }^{a}$ and Nobuo IкотA ${ }^{*, a}$ \\ ${ }^{a}$ Redox Regulation Research Group, National Institute of Radiological Sciences; 4-9-1 Anagawa, Inage-ku, Chiba \\ 263-8555, Japan: and ${ }^{b}$ Faculty of Pharmaceutical Sciences, Teikyo University; 1091-1 Suarasi, Sagamikomachi, Tsukui- \\ gun, Kanagawa 199-0195, Japan. \\ Received August 5, 2003; accepted October 23, 2003; published online October 28, 2003
}

\begin{abstract}
The inhibitory effect on tyrosine nitration and oxidation of peroxynitrite was evaluated for more than 40 reagents including natural and synthetic compounds, and the inhibiting efficiency of each compound for nitration was compared with that for oxidation, to characterize its property as a peroxynitrite scavenger. In the presence of various concentrations of testing compounds, the nitrating and oxidizing activities were measured by monitoring the formation of 3-nitrotyrosine and dityrosine with an HPLC-UV-fluorescence detector. The $\mathrm{IC}_{50}$ values for nitration and oxidation were determined, and the ratio of these two $\mathrm{IC}_{50}$ values was calculated for each compound. Although the $\mathrm{IC}_{50}$ values varied from compound to compound, it was revealed that the ratio of two $\mathrm{IC}_{50}$ values $\left(\mathrm{IC}_{50}\right.$ for oxidation/IC $\mathrm{I}_{50}$ for nitration) was 1 in almost all the compounds tested, except five indole derivatives (L-tryptophan, melatonin, 5-methoxytryptamine, tryptamine, and tetrahydro-beta-carboline) and one synthetic selenium-containing compound $((2 R, 3 R, 4 S)$-2-amino-3,4-dihydroxy-5-phenylselenopentan-1-ol, ADPP). The indole derivatives showed a specific inhibitory effect on tyrosine nitration without affecting the oxidation. ADPP was confirmed to have a preferable inhibitory activity for tyrosine oxidation. It was suggested that compounds showing an $\mathrm{IC}_{50}$ value ratio of 1 scavenged the common species for nitration and oxidation, while the indole derivatives and ADPP preferably scavenged the nitrating and oxidizing species, respectively. From a stopped flow study, it was also revealed that the nitrotyrosine formation was relatively slow, unlike an $\mathrm{OH}$ radical reaction. These results imply that the peroxynirite reaction at least partly proceeds through specific species for nitration.
\end{abstract}

Key words peroxynitrite; nitrotyrosine; tryptamine; scavenger; selenium; dityrosine

Reactive oxygen species are now well-known and important components of oxidative stress in several diseases, such as inflammation, Parkinson's disease, Alzheimer's disease, etc. It has also been suggested that nitric oxide (NO) and its activated species, reactive nitrogen species, are involved in the oxidative damage in such diseases. Peroxynitrite $(\mathrm{PN})$ is known as a reactive nitrogen species, and is thought to be formed from $\mathrm{NO}$ and superoxide $\left.\left(\mathrm{O}_{2}^{-} \cdot\right)_{\text {in vivo. }}{ }^{1,2}\right) \mathrm{PN}$ is a highly reactive oxidant, and causes nitration on the aromatic ring of free tyrosine and protein tyrosine residues. ${ }^{3)}$ Since the nitration of tyrosine residues is a characteristic reaction of $\mathrm{PN}$, the presence of nitrotyrosine in tissues or cell cultures is often used as a marker of PN production, although it was recently reported that myeloperoxidase and nitrite can induce tyrosine nitration in the presence of hydrogen peroxide. ${ }^{4)}$ It was also reported that PN induced various oxidative damage in vitro, for example low density lipoprotein oxidation, lipid peroxidation, DNA strand breakage and so on. ${ }^{5-14)}$ Additionally, tyrosine nitration is thought to affect the phosphorylation of tyrosine residues in substrate proteins of tyrosine kinase in cellular signal transduction. ${ }^{5-17)}$ These data imply that the oxidizing and nitrating reactions of PN may play different pathological roles in the oxidative stress process. From this point of view, it is very useful and important to discriminate the reaction of nitrating (nitrative) damage from that of the oxidative damage in $\mathrm{PN}$-induced oxidative stress reactions.

Various antioxidants have been reported to have an inhibitory effect on the nitration of tyrosine, ${ }^{3,18)}$ as well as oxidation by PN. However, the relationships between these two inhibitory effects of a certain compound have not been quantitatively discussed. We have briefly communicated ${ }^{19)}$ that 5 methoxytryptamine (5MT) and $\alpha$-lipoic acid (LA) are selective inhibitors for tyrosine nitration by PN, but not for oxidative dityrosine formation. In this paper, we report the evaluation and comparison of the inhibiting activity for nitration and oxidation of tyrosine by PN of more than 40 reagents including natural and synthetic compounds, and the elucidation of a unique property of five indole derivatives and one synthetic selenium-containing compound tested.

\section{Experimental}

Chemicals L-Tyrosine and $p$-fluoro-L-phenylalanine were purchased from Wako Pure Chemical Ind. (Osaka, Japan). 3-Nitro-L-tyrosine, 5methoxytryptamine (5MT), melatonin, and tetrahydro- $\beta$-carboline were from Aldrich (Milwaukee, WI, U.S.A.). All reagents purchased were of analytical grade.

Synthetic Compounds $(2 S, 3 R, 4 S)-N-3-[4-H y d r o x y-2,3,5$-trimethylphenoxy]propyl]-3,4-dihydroxy-5-hydroxymethylpyrrolidine (TMP-SRSDHHMP) hydrochloride ${ }^{20)}$ was prepared from 3-[4-[(tert-butyldimethylsilyl)oxy]-2,3,5-trimethyl-phenoxy]propyl bromide ${ }^{21)}$ and $(2 S, 3 R, 4 S)-3,4$-isopropylidenedioxy-5-methoxymethoxymethylpyrrolidine ${ }^{22)}$ in the presence of potassium carbonate in acetone followed by the removal of tert-butyldimethylsilyl and methoxymethoxy protecting groups with tetrabutylammonium fluoride in tetrahydrofuran and with aqueous hydrochloric acid in methanol at $60^{\circ} \mathrm{C}$, respectively.

mp $163-165^{\circ} \mathrm{C}$; ${ }^{1} \mathrm{H}-\mathrm{NMR}\left(\mathrm{D}_{2} \mathrm{O}\right) \delta: 1.90-2.30\left(2 \mathrm{H}, \mathrm{m}, \mathrm{CH}_{2}\right), 2.00$, 2.04, 2.09 ( $3 \mathrm{H}$ each, s each, $\left.3 \times \mathrm{CH}_{3}\right), 3.05-3.80\left(6 \mathrm{H}, \mathrm{m}, 2 \times \mathrm{CH}_{2}\right), 3.85-$ $4.05(3 \mathrm{H}, \mathrm{m}, 3 \times \mathrm{CH}), 4.33-4.55\left(2 \mathrm{H}, \mathrm{m}, \mathrm{CH}_{2}\right), 6.62(1 \mathrm{H}, \mathrm{s}$, aromatic proton); ${ }^{13} \mathrm{C}-\mathrm{NMR}\left(\mathrm{D}_{2} \mathrm{O}\right) \delta: 12.28(\mathrm{q}), 12.86(\mathrm{q}), 16.71(\mathrm{q}), 25.78(\mathrm{t}), 55.07(\mathrm{t})$, $57.06(\mathrm{t}), 58.38(\mathrm{~d}), 67.83(\mathrm{t}), 69.83(\mathrm{t}), 70.80(\mathrm{~d}), 71.44(\mathrm{~d}), 114.56(\mathrm{~d})$, $124.36(\mathrm{~s}), 125.38(\mathrm{~s}), 126.99(\mathrm{~s}), 146.82(\mathrm{~s}), 150.57(\mathrm{~s}) ;[\alpha]_{\mathrm{D}}^{20}+19.3^{\circ}(c=1$, $\mathrm{H}_{2} \mathrm{O}$ ).

All other synthetic compounds were prepared as previously described or 
were generous gifts. (See Table 2 and References and Notes).

Peroxynitrite Preparation PN was synthesized as an alkaline solution based on the method of Pryor et al. ${ }^{23)}$ Briefly, $\mathrm{NaN}_{3}(138 \mathrm{mg}$ ) was dissolved in $10 \mathrm{ml}$ of $\mathrm{H}_{2} \mathrm{O}$, and the solution was then adjusted to $\mathrm{pH} 12$ with $1.5 \mathrm{~N}$ $\mathrm{NaOH}$. The solution was bubbled with an oxygen stream containing ozone (generated at $1 \mathrm{~g} / \mathrm{h}$ by an ozone generator) for $15 \mathrm{~min}$ while in an ice bath, so that the solution gradually turned yellow. The resulting solution was frozen in a dry-ice/acetone bath, and then slightly defrosted at room temperature to collect a concentrated yellow alkaline solution of PN. The obtained PN solution was stored at $-80^{\circ} \mathrm{C}$ until use. The concentration of PN was determined photometrically by measuring the absorbance at $302 \mathrm{~nm}$ ( $\varepsilon=$ $1670 \mathrm{M}^{-1} \mathrm{~cm}^{-1}$ ). Using this method, up to a $240 \mathrm{~mm}$ solution of PN was obtained. The concentration of the stock solution was determined again before use, and then the stock solution was diluted to the desired concentration with $0.01 \mathrm{~N} \mathrm{NaOH}$.

Inhibitory Effect of Various Compounds on the Reaction of Peroxynitrite with L-Tyrosine $\mathrm{PN}(0.2 \mathrm{~mm})$ was added at $37^{\circ} \mathrm{C}$ to the L-tyrosine (1 mM) solution in $0.1 \mathrm{M}$ sodium phosphate buffer $(\mathrm{pH} 7.4)$ containing various concentrations of testing compounds. After 10 -min incubation at $37^{\circ} \mathrm{C}$, $p$-fluorotyrosine (final $0.91 \mathrm{~mm}$ ) was added to the reaction mixture as an internal standard. Due to the short lifetime of PN in the neutral solution, the remaining $\mathrm{PN}$ was thought to decompose during the 10-min incubation. An aliquot of the reaction mixture was analyzed with an HPLC-UV-fluorescence detector system (TOSOH Corp., Tokyo, Japan). The HPLC conditions were as follows; column: TSK-GEL ODS 80 -Ts $4.6 \times 150 \mathrm{~mm}$ (TOSOH Corp., Tokyo, Japan), mobile phase: $0.1 \mathrm{M}$ potassium phosphate ( $\mathrm{pH} 3.5)$, flow rate: $1.0 \mathrm{ml} / \mathrm{min}$. The 3-nitro-L-tyrosine and $2,2^{\prime}$-dityrosine formed were detected by monitoring the absorbance at $274 \mathrm{~nm}$ and the fluorescence at $410 \mathrm{~nm}$ (ex. $295 \mathrm{~nm}$ ), respectively. There was no disturbance in the detection of nitrotyrosine and dityrosine by the testing compounds used in this paper under these analytical conditions. The detected 3-nitro-L-tyrosine was quantified using a standard curve. The formation of dityrosine was confirmed by comparing the retention time and the excitation/fluorescence spectra of a detected peak with the enzymatically synthesized authentic sample, as previously described. ${ }^{19)}$ The percent changes of the produced dityrosine were calculated from the fluorescence peak area. When a testing compound showed inhibitory activity, its $\mathrm{IC}_{50}$ value was determined for 3-nitro-L-tyrosine and for $2,2^{\prime}$-dityrosine formation. ${ }^{25)}$

Stopped Flow Measurement of the Nitration of Tyrosine A product of L-tyrosine and PN, 3-nitriotyrosine has a characteristic local absorption maximum $\left(\lambda_{\max }\right)$ at $274 \mathrm{~nm}$. By monitoring the absorbance change at this wavelength, the production rate of 3-nitrotyrosine was measured. L-tyrosine solution in $0.1 \mathrm{~N} \mathrm{HCl}$ and $\mathrm{PN}$ solution in $0.01 \mathrm{~N} \mathrm{NaOH}$ were mixed, and the absorbance change at $274 \mathrm{~nm}$ was recorded with a stopped flow photometer (Otsuka Electronics Co., LTD, Osaka, Japan). From the observed reaction rate at various concentrations of L-tyrosine and $\mathrm{PN}$, the reaction rate constant was calculated as a second order reaction.

\section{Results and Discussion}

Various compounds, including natural and synthetic compounds, were subjected to the assay for the inhibition of tyrosine nitration and oxidation by PN. In the presence of the testing compound, $0.2 \mathrm{~mm}$ of freshly prepared PN solution was mixed with $1 \mathrm{~mm}$ of L-tyrosine in sodium phosphate buffer at physiological $\mathrm{pH}$. The products were analyzed by HPLC with UV and fluorescence detectors. It was confirmed that 3-nitrotyrosine was formed as a major product of the reaction. The formation of 3-nitrotyrosine was dependent on the concentration of $\mathrm{PN}$ and L-tyrosine, as previously reported. ${ }^{19)}$ The formation of 2,2'-dityrosine was also detected by fluorescence at $410 \mathrm{~nm}($ ex. $295 \mathrm{~nm}) .{ }^{14)}$ The production of 3-nitrityrosine and 2,2'-dityrosine was measured as the nitrated and oxidized products, respectively, and the percentage of production was calculated for the control reaction (containing no testing reagents). Among the more than 40 tested reagents showing an inhibitory effect on either nitration or oxidation, the $\mathrm{IC}_{50}$ values were determined for 26 compounds having sufficient efficacy (Table 1).

To compare and characterize the inhibitory effect of 26 ef- fective compounds, they were each plotted on the graph on which the $\mathrm{X}$-axis represented the $\mathrm{IC}_{50}$ value for the 3-nitrotyrosine formation and the Y-axis the dityrosine formation. It was found that 20 compounds of 26 were plotted on the line of $y=x$, meaning that these compounds have the same inhibiting potency for nitration as for oxidation. It was suggested that these compounds scavenged the common species for both the nitration and oxidation reaction of PN. On the other hand, it was also found that the other 6 compounds, melatonin, 5-methoxytryptamine, tryptamine, tetrahydro-

Table 1. Inhibitory Activity for Tyrosine Nitration and Oxidation by Peroxynitrite

\begin{tabular}{|c|c|c|c|c|}
\hline \multirow{2}{*}{ Compounds } & \multicolumn{2}{|c|}{ 3-Nitrotyrosine } & \multicolumn{2}{|c|}{$2,2^{\prime}$-Dityrosine } \\
\hline & Inhibition & $\mathrm{IC}_{50}(\mathrm{~mm})$ & Inhibition & $\mathrm{IC}_{50}(\mathrm{~mm})$ \\
\hline Glutathione & + & 0.04 & + & 0.042 \\
\hline Melatonin & + & 0.289 & - & - \\
\hline $5 \mathrm{MT}$ & + & 0.438 & - & - \\
\hline DTCP $^{26)}$ & + & 0.032 & + & 0.035 \\
\hline $\mathrm{ADPP}^{27)}$ & + & 1.53 & + & 0.154 \\
\hline $\mathrm{NEMP}^{27)}$ & + & 0.038 & + & 0.038 \\
\hline $\mathrm{APCB}^{27)}$ & + & 0.5 & + & 0.372 \\
\hline Tryptamine & + & 1.8 & - & - \\
\hline $3^{\prime} 4^{\prime}-\mathrm{DHBnTIQ}{ }^{28)}$ & + & 0.07 & + & 0.06 \\
\hline 67-DHBnTIQ ${ }^{28)}$ & + & 0.05 & + & 0.05 \\
\hline Curcumin & + & 0.020 & + & 0.017 \\
\hline $\mathrm{PBN}$ & $(+)$ & $>2$ & $(+)$ & $>2$ \\
\hline Uric acid & + & 0.025 & + & 0.025 \\
\hline Catechin & + & 0.01 & + & 0.005 \\
\hline $\mathrm{RKO}^{2} \mathrm{~B}^{29)}$ & + & 0.0178 & + & 0.014 \\
\hline $\mathrm{RK} 18 \mathrm{R}^{30)}$ & + & 0.016 & + & 0.016 \\
\hline RK16O ${ }^{31)}$ & + & 0.039 & + & 0.023 \\
\hline Trolox & + & 0.017 & + & 0.02 \\
\hline $\mathrm{THCL}^{32)}$ & + & 0.007 & + & 0.006 \\
\hline $\mathrm{HTP}^{33)}$ & + & 0.023 & + & 0.019 \\
\hline $\mathrm{DDFC}^{34)}$ & + & 0.015 & + & 0.018 \\
\hline Tetrahydro- $\beta$-carboline & + & 1.0 & - & - \\
\hline L-Tryptophan & + & 2.0 & - & - \\
\hline $\mathrm{TMG}^{35)}$ & + & 0.022 & + & 0.022 \\
\hline MS- $818^{36)}$ & $(+)$ & $>2(5.0)$ & $(+)$ & $>2(4.2)$ \\
\hline НТРP & + & 0.018 & + & 0.020 \\
\hline
\end{tabular}

$\mathrm{IC}_{50}$ values are calculated from the dose-dependent curve determined from at least three independent experiments for $1 \mathrm{~mm}$ tyrosine and $0.2 \mathrm{~mm}$ peroxynitrite. + : inhibitory effect was observed, $(+)$ : inhibitory effect was observed but very weak, - : inhibitory effect was not observed at all in the range of this work.

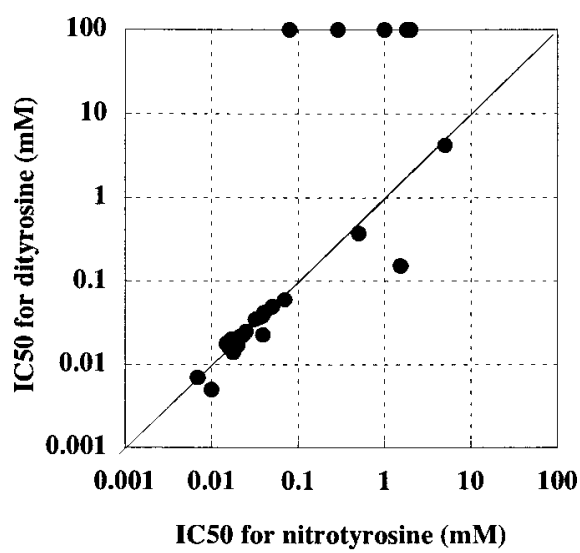

Fig. 1. Comparison of $\mathrm{IC}_{50}$ Values for Nitration and Oxidation of Tyrosine with Peroxynitrite

$\mathrm{IC}_{50}$ values of the compounds for nitrotyrosine and dityrosine formation were determined for $1 \mathrm{~mm}$ of tyrosine and $0.2 \mathrm{~mm}$ peroxynitrite as described in Experimental. 
beta-carboline, tryptophan, and ADPP were plotted out of the $\mathrm{y}=\mathrm{x}$ line (Fig. 1). Melatonin, 5-methoxytryptamine, tryptamine, tetrahydro-beta-carboline, and tryptophan, which contain indole moiety, showed an inhibitory effect only on the nitration of tyrosine, and were plotted far above the line. This result indicates that these compounds apparently scavenge the specific species promoting the nitrating reaction. In contrast, ADPP, a selenium-containing synthetic compound, was plotted below the line, indicating that this compound scavenged the species for oxidation more effectively than that for nitration.

From the results of the reaction rate measurements using a stopped-flow method, the reaction rate constant for the tyrosine nitration was found to be $3.63 \times 102 \mathrm{M}^{-1} \mathrm{~s}^{-1}$ as the sec-

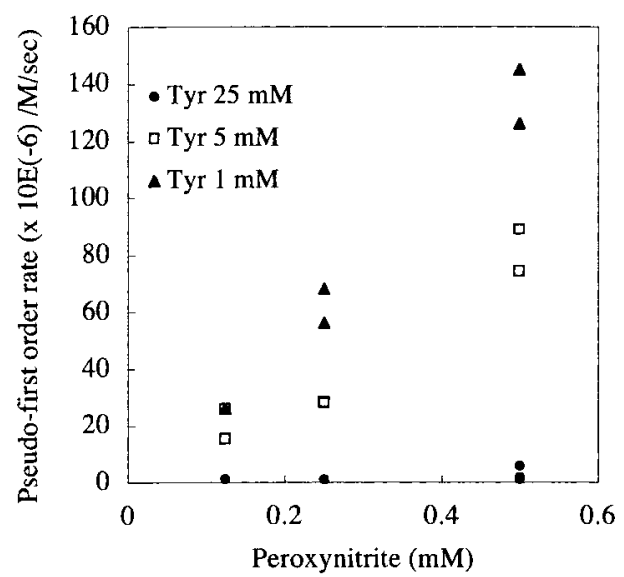

Fig. 2. Kinetics of the Reaction between Tyrosine and Peroxynitrite

Pseudo first order rates were determined by the stopped-flow method using indicated concentrations of L-tyrosine and synthetic peroxynitrite. The second order rate constant was calculated from the pseudo first order rates. ond order rate constant (Fig. 2). This value was comparable to the rate for tryptophan as previously reported. ${ }^{24)}$ It is known that the reactivity of PN for the oxidation is similar to $\mathrm{OH}$ radicals, which is a diffusion rate-determining reaction, whereas the rate constant for the nitration calculated in this experiment was much smaller than that for the $\mathrm{OH}$ radical reaction. This result suggests that the nitrating reaction has a different rate-limiting step. In the light of this result, the nitrating reaction is not likely to be a direct rebound reaction of caged $\mathrm{NO}_{2}$ radicals after electron subtraction by caged $\mathrm{OH}$ radicals from the aromatic ring of tyrosine.

It is known that PN couples with carbon dioxide to form more reactive species. In our system, all the experiments were conducted without additional carbon dioxide, so our results may not be directly applicable to the carbonate containing conditions such as in cell culture with carbonate ions, or in serum in the veins. However, when the PN reaction with tyrosine was carried out in Earle's buffered salt solution containing bicarbonate ions, 5-methoxytryptamine actually inhibited the nitration of tyrosine selectively without inhibiting the dityrosine formation. Therefore, it is still likely that there are different species or steps for tyrosine nitration by PN even in the presence of carbonate ions.

In conclusion, almost all the compounds tested in this experiment, including antioxidants, showed equal inhibitory activity for both nitration and oxidation, suggesting that these compounds scavenged the common species for nitration and oxidation. However, five indole derivatives, tested selectively, inhibited tyrosine nitration, suggesting that they scavenged specific species for nitration. In contrast, ADPP, a seleniumcontaining compound, preferentially inhibited dityrosine formation. Together with our results, it was suggested that there may be specific species for tyrosine nitration by PN different

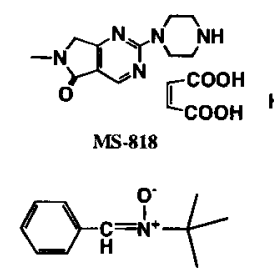

PBN<smiles>O=c1[nH]c(=O)c2[nH]c(=O)[nH]c2[nH]1</smiles><smiles>COc1ccc2[nH]cc(CCNC(C)=O)c2c1</smiles><smiles>N[C@H](CC1CNc2ccccc21)C(=O)O</smiles>

L-Tryptophan<smiles>CCCCCCOC1C=C(C)[C@H](O)[C@H](C)C1C</smiles>

HTP<smiles>O=C(O)[C@H]1CCCN1C(=S)S</smiles><smiles>[Te]=[Te]</smiles><smiles>O=C(/C=C/C1CCC(O)C(O)C1)C1CCC(O)CC1O</smiles>

THCL<smiles>CC1C(O)C2CCC3(CO)OC(C)(CO)CC23C1C</smiles>

Trolox<smiles>COC1CC(CCC(=O)CCCC2CC(C)C(O)C2)CCC1O</smiles>

Curcumin

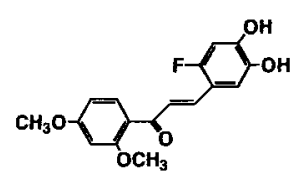

DDFC<smiles>CC1C(O)C(C)C(CCCN2CC(O)C(O)C2C)C1O</smiles><smiles>COCC1(C)CCc2c(C)c(O)c(C)c(C)c2O1</smiles><smiles>OC1CC2CCC(O)C2CC1C1CCCC1</smiles>

67DHBnT10

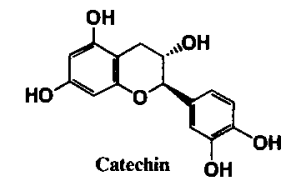

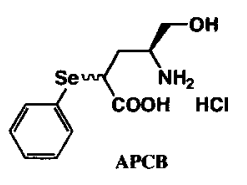<smiles>O=C(O)C1CCCCC1Cc1ccc(O)c(O)c1</smiles><smiles>OC[C@@H]1[C@@H](O)[C@@H](O)CN1CCS</smiles>

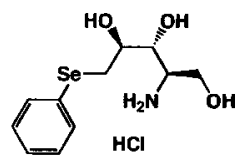

1,2,3,4-Tetrahydro- $\beta$-carboline

ADPP

Fig. 3. Structures of Synthetic and Natural Compounds Used 
to the specie for the oxidation reaction. The rate-determining step for nitration was assumed to be very slow compared with the $\mathrm{OH}$ radical-like reaction of $\mathrm{PN}$. It was also demonstrated that the nitrating reaction of PN could be distinguished from the oxidizing reaction using these specific inhibiting compounds.

Acknowledgments The authors acknowledge the late Professor Toshio Satoh and Dr. Hideki Miyataka, Tokushima Bunri University, Professor Tsutomu V. Kagiya, Kinki Research Foundation, Professor Shigeru Ohta and Dr. Yaichiro Kotake, Hiroshima University, and Dr. Akira Awaya, for kindly providing the valuable compounds. Partial financial support by a Grant-inAid for Scientific Research (No. 10357021, 11771475) from Ministry of Education, Culture, Science, Sports and Technology Japan, and a grant from the Cosmetology Research Foundation are gratefully acknowledged. This study was performed using Special Coordination Funds of the Ministry of Education, Culture, Sports, Science and Technology, Japan.

\section{References and Notes}

1) Beckman J. S., Beckman T. W., Chen J., Marshall P. A., Freeman B. A., Proc. Natl. Acad. Sci. U.S.A., 87, 1620-1624 (1990).

2) Huie R. E., Padmaja S., Free Radic. Res. Commun., 18, 195-199 (1993).

3) Whiteman M., Tritschler H., Halliwell B., FEBS Lett., 379, 74-76 (1996b)

4) Sampson J. B., Ye Y., Rosen H., Beckman J. S., Arch. Biochem. Biophys., 15, 207-213, (1998).

5) Darley-Usmar V., Wiseman H., Halliwell B., FEBS Lett., 369, 131135 (1995).

6) Darley-Usmar V. M., Hogg N. O., Leary V. J., Wilson M. T., Moncada S., Free Radic. Res. Commun., 17, 9-20 (1992).

7) White C. R., Brock T. A., Chang L. Y., Crapo J., Briscoe P., Ku D., Bradley W. A., Gianturco S. H., Gore J., Freeman B. A., Tarpey M. M., Proc. Natl. Acad. Sci. U.S.A., 91, 1044-1048 (1994).

8) Salgo M. G., Bermudez E., Squadrito G. L., Pryor W. A., Arch. Biochem. Biophys., 322, 500-505 (1995).

9) Squadrito G. L., Jin X., Pryor W. A., Arch. Biochem. Biophys., 322, 53-59 (1995).

10) Radi R., Beckman J. S., Bush K. M., Freeman B. A., Arch. Biochem. Biophys., 288, 481—487 (1991).

11) Radi R., Beckman J. S., Bush K. M., Freeman B. A., J. Biol. Chem., 266, 4244- 4250 (1991).

12) King P. A., Anderson V. E., Edwards J. O., Gustafson G., Plumb R. C., Suggs J. W., J. Am. Chem. Soc., 114, 5430-5432 (1992).

13) Pryor W. A., Jin X., Squadrito G. L., Proc. Natl. Acad. Sci. U.S.A., 91, 11173-1117 (1994).

14) Van der Vliet A. O., Neill C. A., Halliwell B., Cross C. E., Kaur H., FEBS Lett., 339, 89-92 (1994).

15) Kong S. K., Yim M. B., Stadtman E. R., Chock P. B., Proc. Natl. Acad. Sci. U.S.A., 93, 3377-3382 (1996).

16) Gow A. J., Duran D., Malcolm S., Ischiropoulos H., FEBS Lett., $\mathbf{3 8 5}$, 63-66 (1996).

17) Li X., DeSarno P., Song L., Beckman J. S., Jope R. S., Biochem. J., 331, 599-606 (1998).

18) Whiteman M., Halliwell B., Free Radic. Res., 25, 275-283 (1996a).

19) Nakagawa H., Sumiki E., Ikota N., Matsushima Y., Ozawa T., Antioxi.
Redox Signaling, 1, 239-244 (1999).

20) Ikota N., Ueda J.-I., Gamage R., Shimazu Y., Hama-Inaba H., Takusakawa M., Ozawa T., Satoh T., "Biodefence Mechanisms against Environmental Stress," eds. by Ozawa T., Tatsumi K., Hori T., Kodansha, Tokyo, 1998, pp. 1-12.

21) Yoshioka T., Fujita T., Kanai K., Aigawa Y., Kurumada T., Hasegawa K., Horikoshi H., J. Med. Chem., 32, 421-428 (1989).

22) Ikota N., Heterocycles, 36, 2035-2050 (1993).

23) Pryor W. A., Cueto R., Jin X., Koppenol W. H., Ngu-Schwemlein M., Squadrito G. L., Uppu P. L., Uppu R. M., Free Radic. Biol. Med., 18, 75-83 (1995).

24) Radi R., Chem. Res. Toxicol., 11, 720-721 (1998).

25) Nakagawa H., Ohshima Y., Takusagawa M., Ikota N., Takahashi Y., Shimizu S., Ozawa T., Chem. Pharm. Bull., 49, 1547-1554 (2001).

26) $N$-Dithiocarboxy-L-proline (DTCP) was prepared as previously described: Nakagawa H., Ikota N., Ozawa T., Masumizu T., Kohno M., Biochem. Mol. Biol. Int., 45, 1129-1138 (1998).

27) $(2 S, 3 R, 4 S)$-2-Amino-3,4-dihydroxy-5-phenylselenopentan-1-ol (ADPP), $(2 S, 3 R, 4 S)$ - $N$-ethylmercapto-3,4-dihydroxy-2-hydroxymethylpyrrolidine (NEMP), and (2S,4RS)-2-amino-4-phenylseleno-5-carboxybutan-1ol (APCB) were prepared as previously described: Nakagawa H., Sumiki E., Takusagawa M., Ikota N., Matsushima Y., Ozawa T., Chem. Pharm. Bull., 48, 261-265 (2000).

28) 1-(3',4'-Dihydroxybenzyl)-1,2,3,4-tetrahydroisoquinoline (3' $4^{\prime} \mathrm{DHBn}-$ TIQ) and 1-benzyl-6,7-dihydroxy-1,2,3,4-tetrahydroisoquinoline (67DHBnTIQ) are generous gifts from Professor Shigeru Ohta and Dr. Yaichiro Kotake: Kawai H., Makino Y., Hirobe M., Ohta S., J. Neurochem., 70, 745-751 (1998).

29) 3'-Hydroxy-4'-O-methylglabridin (RK02B): Kinoshita T., Kajiyama K., Hiraga Y., Takahashi K., Tamura Y., Mizutani K., Heterocycles, 43, 581-588 (1996).

30) Glabrocoumarone A (RK18R): Kinoshita T., Kajiyama K., Hiraga Y., Takahashi K., Tamura Y., Mizutani K., Chem. Pharm. Bull., 44, 1218-1221 (1996).

31) Glabrol (RK16O): Saitoh T., Kinoshita T., Shibata S., Chem. Pharm. Bull., 24, 752-755 (1976).

32) 2',4',3,4-Tetrahydroxychalcone (THCL): Sogawa S., Nihiro Y., Ueda H., Miki T., Matsumoto H., Satoh T., Biol. Pharm. Bull., 17, 251-256 (1994).

33) 4-Hexyloxy-2,3,6-trimethylphenol (HTP) was prepared as previously described: Nihiro Y., Furukawa H., Sogawa S., Wang T.- C., Miyataka H., Matsumoto H., Miki T., Satoh T., Chem. Pharm. Bull., 42, 576579 (1994).

34) 2',4'-Dimethoxy-3,4-dihydroxy-6-fluorochalcone (DDFC) was a generous gift from the late Professor Toshio Satoh: Nakamura C., Kawasaki N., Miyataka H., Jayachandran E., Kim I.-H., Kirk K. L., Taguchi T., Takeuchi Y., Hori H., Satoh T., Bioorg. Med. Chem., 10, 699-706 (2002)

35) 2-( $\alpha$-D-Glucopyranosyl)methyl-2,5,7,8-tetramethylchroman-6-ol (TMG) was obtained from CCI Corporation, Gifu, Japan by Professor Tsutomu V. Kagiya: Murase H., Yamauchi R., Kato K., Kunieda T., Terao J., Lipids, 32, 73-78 (1997).

36) 2-Piperadino-6-methyl-5-oxo-5,6-dihydro(7H)-pyrrolo[3,4- $d]$ pyrimidine maleate (MS-818) was a generous gift from Dr. Akira Awaya: Awaya A., Kobayashi H., Horikomi K., Tanaka S., Kabir A. M., Yokoyama K., Ohno H., Kato K., Kitahara T., Tomino I., Isayama S., Nakamura S., Biol. Pharm. Bull., 16, 248-253 (1993). 